\title{
Complementary nature of surface and atmospheric parameters associated with Haiti earthquake of 12 January 2010
}

\author{
Ramesh P. Singh ${ }^{1,2}$, Waseem Mehdi ${ }^{2}$, and Manish Sharma ${ }^{2}$ \\ ${ }^{1}$ School of Earth and Environmental Sciences, Schmid College of Science, Chapman University, One university Drive, \\ Orange, CA 92866, USA \\ ${ }^{2}$ Research and Technology Development Center, Sharda University, Greater Noida, India
}

Received: 21 April 2010 - Revised: 6 June 2010 - Accepted: 7 June 2010 - Published: 22 June 2010

\begin{abstract}
The present paper describes surface (surface air temperature) and atmospheric parameters (relative humidity, surface latent heat flux) over the epicenter $\left(18^{\circ} 27^{\prime} 25^{\prime \prime} \mathrm{N}\right.$ $72^{\circ} 31^{\prime} 59^{\prime \prime} \mathrm{W}$ ) of Haiti earthquake of 12 January 2010 . Our analysis shows pronounced changes in surface and atmospheric parameters few days prior to the main earthquake event. Changes in relative humidity are found from the surface up to an altitude of $500 \mathrm{hPa}$ clearly show atmospheric perturbations associated with the earthquake event. The purpose of this paper is to show complementary nature of the changes observed in surface, atmospheric and meteorological parameters. The total ozone concentration is found to be lowest on the day of earthquake and afterwards found to be increased within a week of earthquake. The present results show existence of coupling between lithosphere-atmosphere associated with the deadly Haiti earthquake.
\end{abstract}

\section{Introduction}

Haiti earthquake $\left(M_{\mathrm{w}} 7.0\right)$ of 12 January 2010 occurred at 21:53:10 UTC in the boundary region separating the Caribbean plate and the North America plate. The epicenter of the earthquake is located at latitude $18^{\circ} 27^{\prime} 25^{\prime \prime} \mathrm{N}$ and longitude $72^{\circ} 31^{\prime} 59^{\prime \prime} \mathrm{W}$, focal depth $13 \mathrm{~km}$ according to USGS. The focal mechanism shows that the fault is dominated by left-lateral strike slip and compression, and accommodates about $20 \mathrm{~mm} / \mathrm{y}$ slip, with the Caribbean plate moving eastward with respect to the North American plate (Fig. 1a). Figure $1 \mathrm{~b}$ shows the epicenter of the earthquake which is taken from USGS. About three million people are displaced by this killer earthquake (as reported by International Federation

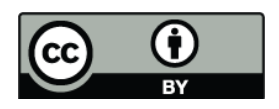

Correspondence to: Ramesh P. Singh (rsingh@ chapman.edu) of Red Cross). This earthquake killed 230000 and thousands were found to be buried beneath the collapsed structures (Bilham, 2010). Number of important buildings were damaged or destroyed, including the Presidential Palace, the National Assembly building, the Port-au-Prince Cathedral, and the main jail. The headquarters of the United Nations Stabilization Mission in Haiti (MINUSTAH), located in the capital, collapsed that killed many people (Fierro and Perry, 2010). A series of aftershocks further threaten life of people living in the region. After eight days, there was a strong aftershock of 6.1-magnitude associated with the main earthquake of 12 January 2010, there were many other aftershocks of $M 5$ (Fig. 1c, http://en.wikipedia.org/wiki/File: Haiti_2010_history.svg).

Numerous surface, atmospheric and ionospheric parameters are found to show complementary nature which provide evidence for the existence of strong coupling associated with some damaging earthquakes (Gujarat earthquake of 26 January 2001, Denali earthquake of 3 November 2002, Sumatra tsunami and earthquake of 26 December 2004, Wenchuan earthquake of 12 May 2008) where pronounced changes in surface temperature, surface latent heat flux, chlorophyll concentrations in ocean, total ozone content, atmospheric water vapor and also in total electron content were found (Dey and Singh, 2003; Dey et al., 2004; Okada et al., 2004; Trigunait et al., 2004; Genzano et al., 2007; Singh et al., 2001a, b, c, 2006, 2007). Anomalous changes on ground, atmosphere and ionosphere were found to be associated with several earthquakes occurred in China, Russia, Japan, Taiwan and Europe (Cioni et al., 2007; Omori et al., 2007; Sharma et al., 2007; Walia et al., 2006; Yasuka et al., 2006; Hayakawa and Hobara, 2010; Singh et al., 2010a, b). A recent special issue of Natural Hazards and Earth System Sciences edited by Contadakis, Biagi and Hayakawa (2009) includes number of papers showing changes on land, atmosphere and ionosphere prior to the Abruzzo earthquake

Published by Copernicus Publications on behalf of the European Geosciences Union. 

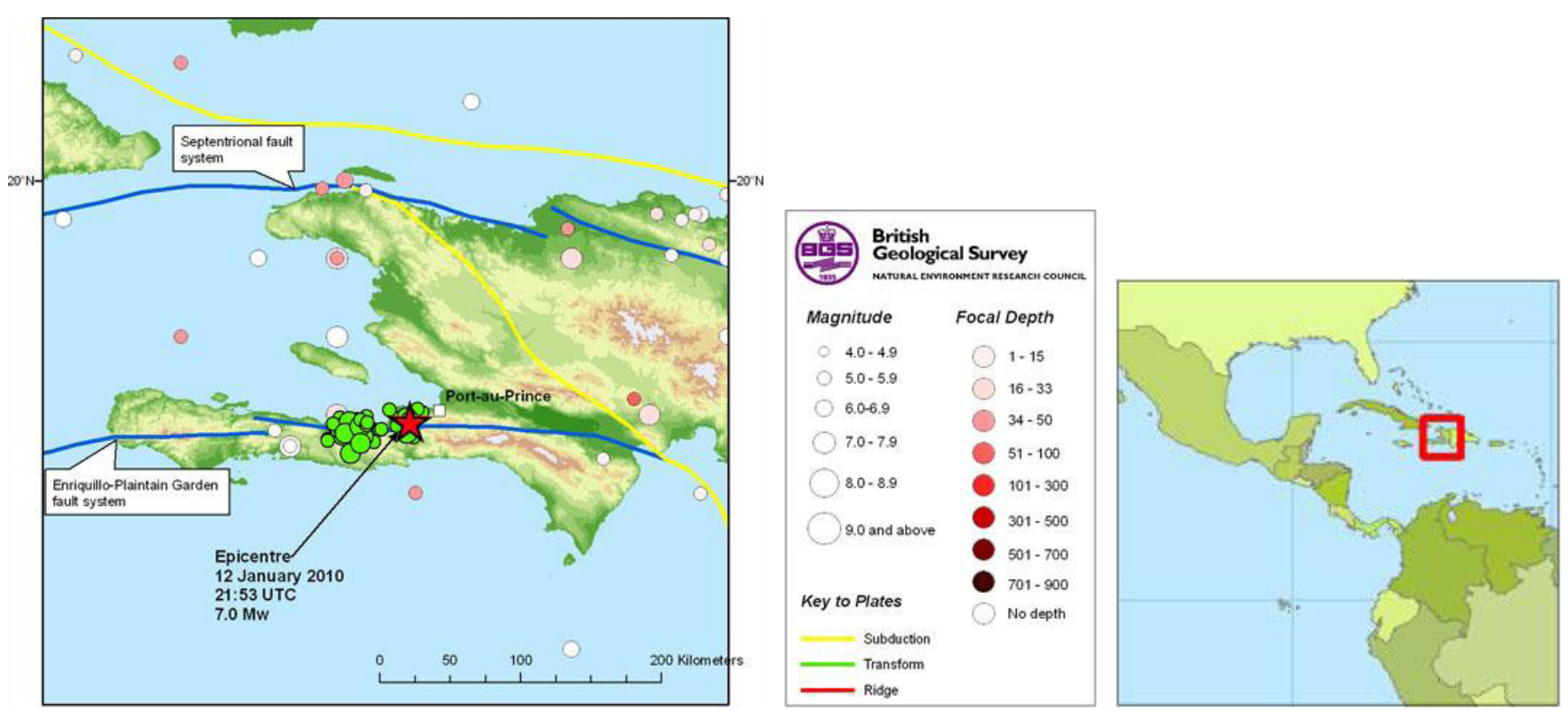

Fig. 1a. Showing location of epicenter of Haiti earthquake event of 12 January 2010 (source: http://www.bgs.ac.uk/research/highlights/ haitiEarthquakeJan2010.html).

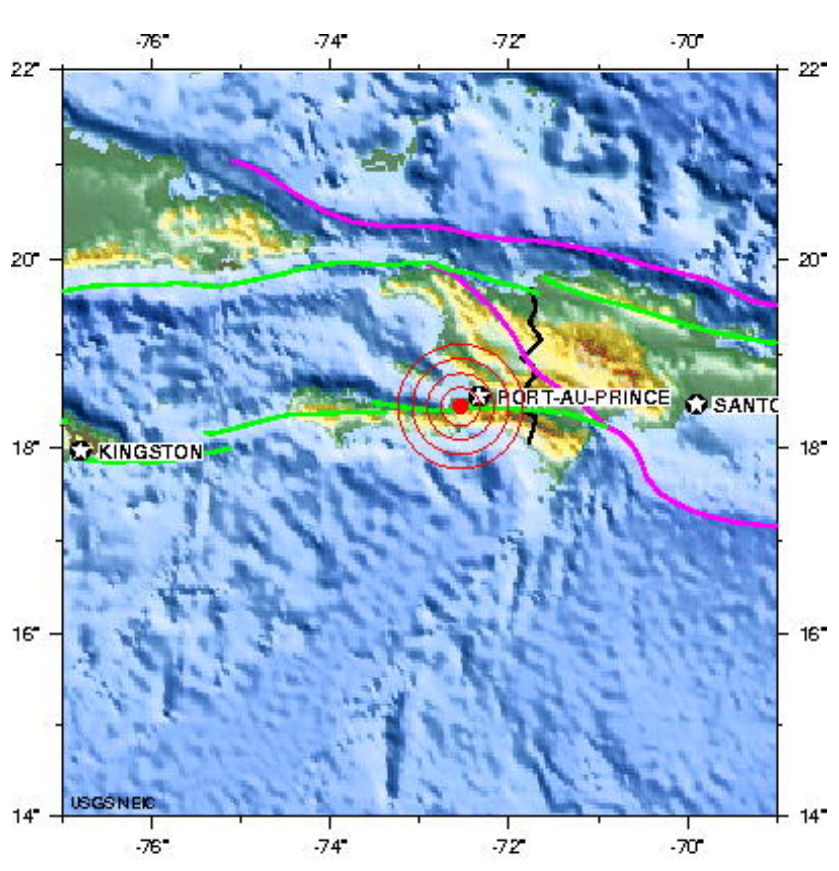

HAITI REGION

201001 1221:53:10 UTC 18.44N 72.54W Depth: $13 \mathrm{~km}$, Magnitude: 7.0 Earthquake Location

Fig. 1b. Epicenter location (source: USGS).

of 6 April 2009 in Italy. Recently, Singh et al. (2010a) have observed carbon monoxide anomaly few days prior to the Gujarat earthquake of 26 January 2001, that shows complementary nature with the observed thermal, surface latent

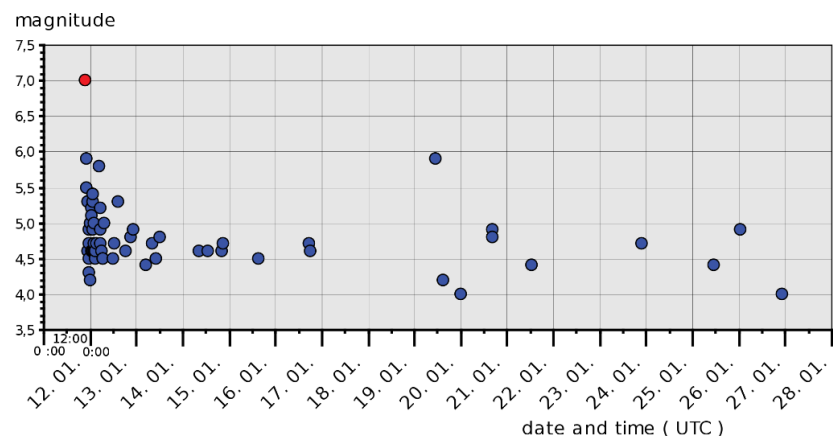

Fig. 1c. Figure 1c shows aftershocks observed in and around epicenetral region in the month of January 2010 (source: http://en.wikipedia.org/wiki/File:Haiti_2010_history.svg).

heat flux and ionospheric perturbations showing existence of land-atmosphere-ionosphere coupling associated with the Gujarat earthquake. These recent observations prompted us to analyze surface and atmospheric parameters of the Haiti earthquake using multi sensor satellite, NCEP reanalysis and ground observatory data to find the complementary changes in surface and atmospheric parameters associated with this earthquake. A pronounced changes in various parameters few days prior show complementary nature that provides evidence of strong coupling between the land-atmosphere associated with this earthquake. 


\subsection{The Haiti earthquake of 12 January 2010}

Haiti occupies the western part of the island of Hispaniola, one of the Greater Antilles islands, situated between Puerto Rico and Cuba. At the longitude of the 12 January earthquake, motion between the two Caribbean and North American plates is partitioned between two major east-west trending, strike-slip fault systems - the Septentrional fault system in northern Haiti and the Enriquillo-Plaintain Garden fault system in southern Haiti. The location and focal mechanism of the earthquake are consistent with the event having occurred as left-lateral strike slip faulting on the EnriquilloPlaintain Garden fault system (EPGFZ). This fault system accommodates about $7 \mathrm{~mm} / \mathrm{y}$, nearly half the overall motion between the Caribbean plate and North America plate.

The Enriquillo-Plaintain Garden fault system has not produced a major earthquake in recent decades. The EPGFZ is the likely source of historical large earthquakes in 1860, $1770,1761,1751,1684,1673$, and 1618, though none of these has been confirmed in the field as associated with this fault. This earthquake did not produce any surface rupture and it is expected some of the energy must be stored in the uppermost few kilometer of the fault (Bilham, 2010).

\subsection{Surface and atmospheric data}

We have taken various surface and atmospheric data over the epicenter $\left(18^{\circ} 27^{\prime} 25^{\prime \prime} \mathrm{N} 72^{\circ} 31^{\prime} 59^{\prime \prime} \mathrm{W}\right)$ of the earthquake. We have considered daily data from NCEPNCAR (http://iridl.ldeo.columbia.edu/SOURCES/.NOAA/ .NCEP-NCAR/.CDAS-1/.DAILY/.Diagnostic/), this data set is represented by the Gaussian grid of 94 lines from equator to pole with a regular $1.8^{\circ}$ longitudinal spacing and AIRS data http://acdisc.sci.gsfc.nasa.gov/Giovanni/airs/airs3d. airsl3.shtml) with resolution $1^{\circ} \times 1^{\circ}$. The NCEP dataset is projected into a $2^{\circ} \times 2^{\circ}$ grid size.

We have taken relative humidity data at various pressures levels $-1000,700$, and $500 \mathrm{hPa}$; surface skin temperature, surface air temperature at a height of $2 \mathrm{~m}$ above ground and surface latent heat flux (SLHF) from NCEP reanalysis data source (http://iridl.ldeo.columbia.edu/SOURCES/ .NOAA/.NCEP-NCAR/.CDAS-1/.DAILY/.Diagnostic/).

\section{Results and discussion}

We have taken daily surface and atmospheric parameters in the present study for one year period over the epicenter of this earthquake. The results are discussed in the following section.

\subsection{Surface air temperature}

Figure 2a shows daily surface air temperature at a height of $2 \mathrm{~m}$ above ground at the epicenter location for the period July 2009-January 2010. A low surface temperature

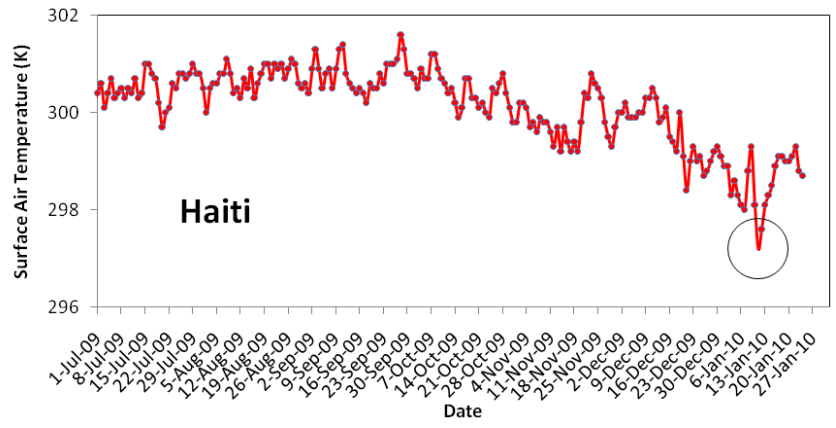

Fig. 2a. Figure 2a shows variation of surface temperature over the epiceneter during July 2009 to January 2010. A lowest surface temperature is observed over the epicenter one day prior to the main earthquake event.

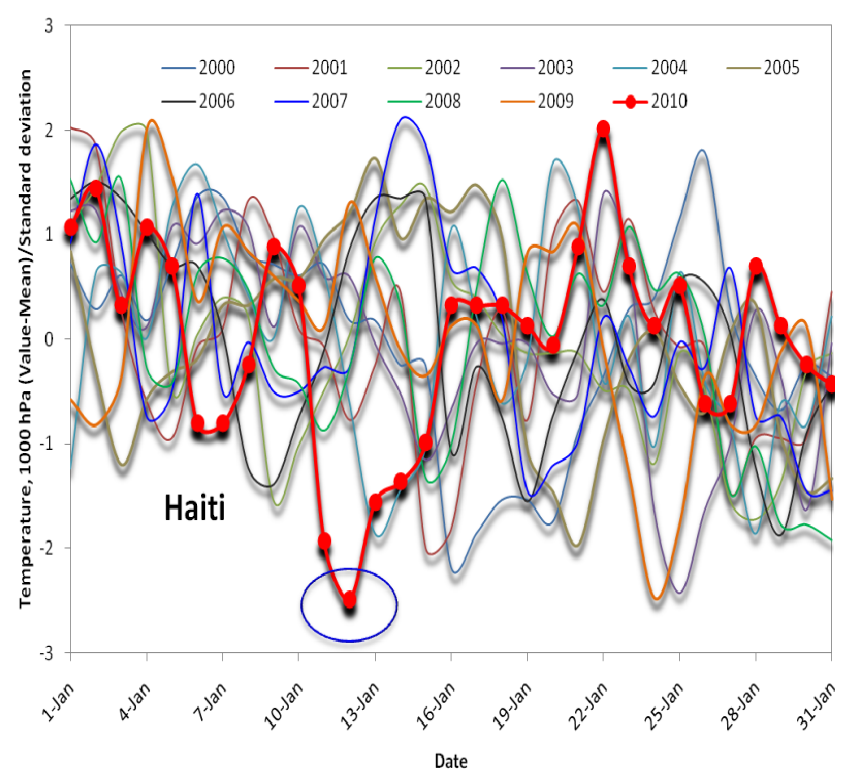

Fig. 2b. Figure $2 b$ shows variation of daily surface air temperature anomaly computed from AIRS data over the epicenter of Haiti earthquake.

(about $297 \mathrm{~K}$ ) is clearly observed one day prior to the earthquake (Fig. 2a), soon after the earthquake surface temperature is found to increase. Figure $2 b$ shows surface temperature anomaly [(value-average value)/standard deviation] over the epicenter.

In Fig. $2 b$, the surface temperature daily anomaly from AIRS data is shown at $1000 \mathrm{hPa}$ pressure level during 131 January for the years 2000-2010, a low surface temperature anomaly is observed one day prior to the earthquake event i.e. 11 January 2010. This is the lowest value found in January compared to the years 2000-2009. A low air temperature over the epicenter of Haiti earthquake is observed at different pressure levels i.e. $1000,850,700$, and $500 \mathrm{hPa}$ and also ground temperature showing complementary nature with the observed temperature anomaly one day prior 


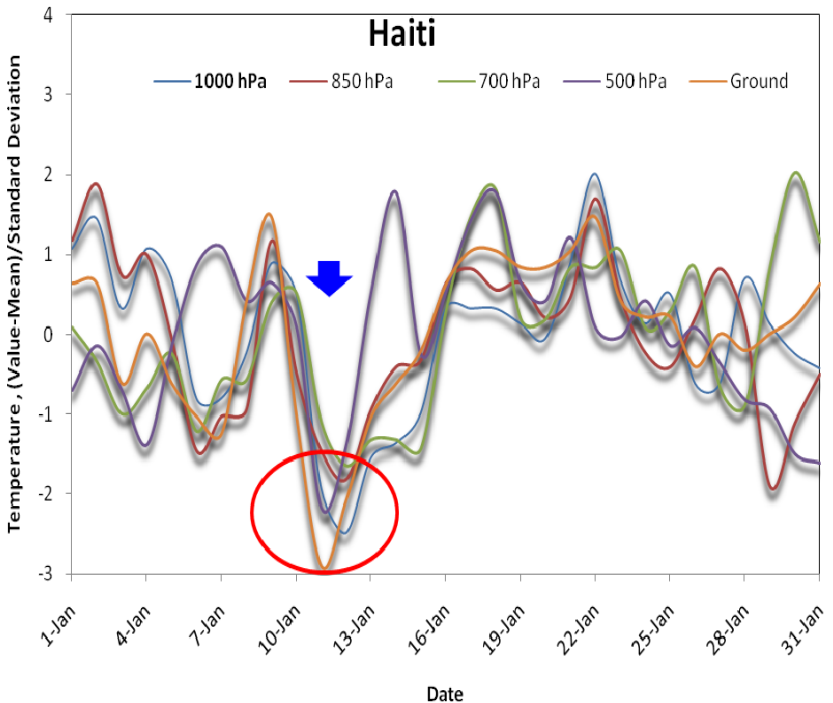

Fig. 2c. Figure $2 c$ shows complementary nature of air temperature anomaly at different pressure levels during in the month of January 2010. A lowest temperature anomaly is observed on 11 January 2010, one day prior to the main earthquake event.

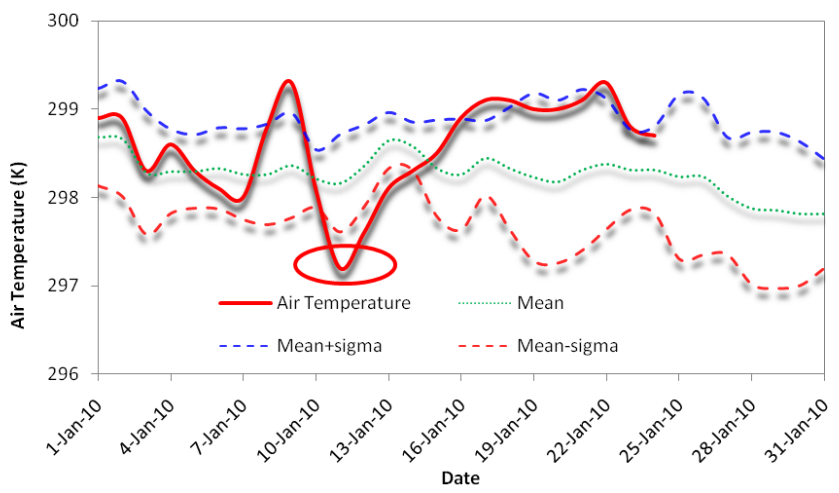

Fig. 2d. Figure $2 d$ shows a minima peak of air temperature one day prior to the earthquake, this minima peak is found to be much lower than mean minus one sigma value of air temperature which is shown in dotted red color. The mean value is shown in dotted green color.

to the main event of the earthquake. The lowest temperature anomaly corresponds to the ground and low pressure levels and the magnitude of the low temperature anomaly is found to decrease with the low pressure levels i.e. at higher altitudes, e.g. on the ground temperature anomaly is found to be $3{ }^{\circ} \mathrm{C}$ whereas at $500 \mathrm{hPa}$ the temperature anomaly is observed to be about $2{ }^{\circ} \mathrm{C}$ (Fig. 2c). Figure $2 \mathrm{~d}$ shows a minima peak of air temperature one day prior to the earthquake, this minima peak is found to be much lower than mean minus one sigma value of air temperature which is shown in dotted red color. The daily mean value for the month of January during 2005-2010 is shown in dotted green color.

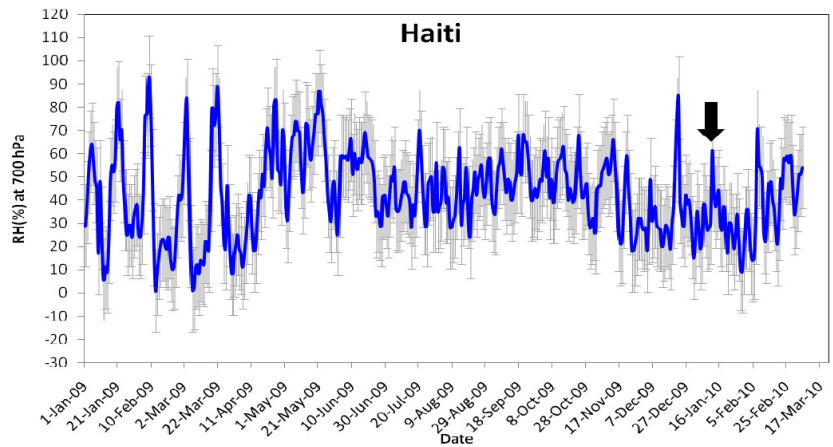

Fig. 3a. Figure 3a shows daily variations of relative humidity over the epicenter at $700 \mathrm{hPa}$ with one standary deviation (error bars) for the period Januray 2009 - March 2010. A higher peak in relative humdity is observed one day prior to the earthquake event, however such peaks in relative humidity are also observed which may be associated with the atmospheric perturbations.

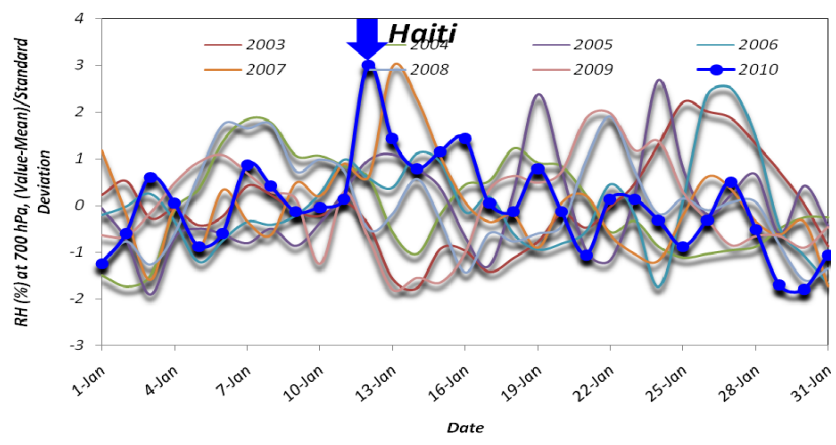

Fig. 3b. Figure 3b shows anomaly in relative humidity at $700 \mathrm{hPa}$, the nature of variations of relative humdity is showing maxima peak on the day of earthquake. The variations of relative humdity show characteristics nature for the 2010 variations compared to other years. The anomalous peaks are although common which could be assocaited with the changes in atmospheric perturbations.

\subsection{Relative humidity}

In Figs. 3a, b, c, and d daily relative humidity from AIRS data are shown for period (July 2009-January 2010) at 1000, 850 , and $700 \mathrm{hPa}$ pressure levels. The daily relative humidity variations show number of maxima and minima peaks. Such peaks are common due to atmospheric disturbances and sudden change in weather conditions, such characteristics are also observed during monsoon period. The daily variations of relative humidity shows a higher value on 11 January 2010 at pressure levels 1000 to $500 \mathrm{hPa}$, variations of daily surface latent heat flux with error bars (one standard deviation) is shown in Fig. 3a for pressure level $700 \mathrm{hPa}$. Although on other days higher peaks in relative humidity is seen on other days. 


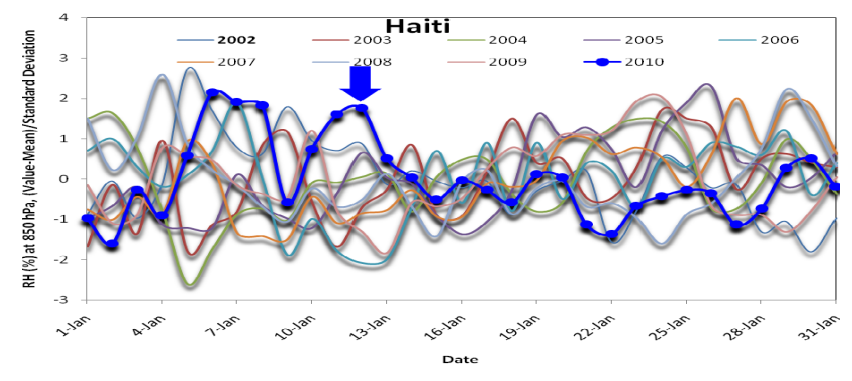

Fig. 3c. Figure $3 c$ shows daily anomaly in relative humidity at $850 \mathrm{hPa}$, the nature of variations of relative humdity for 2010 shows higher anomaly value compared to other years around the day of earhquake event. The anomalous peaks are although common which could be assocaited with the changes in atmospheric perturbations.

In Figs. $3 \mathrm{~b}$ and c, one day prior to the earthquake event (11 January 2010) a pronounced anomaly of relative humidity is observed, this peak is prominent compared to other peak in relative humidity observed in other years. The magnitude of the relative humidity anomaly is higher at the pressure level $700 \mathrm{hPa}$ (Fig. 3b). At the pressure level $850 \mathrm{hPa}$, the relative humidity anomaly is found to be low compared to the pressure level $750 \mathrm{hPa}$ but this anomaly is prominent compared to others years 2002-2009. At a low pressure levels e.g. $500 \mathrm{hPa}$ and even lower pressure levels, the peak is not very prominent (not shown). The vertical variations of relative humidity for the period 9-17 January 2010 are shown in Fig. 3d, the vertical variation of relative humidity on 1112 January 2010 show all together different characteristics, on these two days the relative humidity is found to be higher compared to other days at the pressure level $850-700 \mathrm{hPa}$. At the lower pressure levels, i.e. $300 \mathrm{hPa}$ the relative humidity is found to be highest on 11 January 2010 compared to other days.

\subsection{Surface latent heat flux}

First time, Dey and Singh (2003) found an anomalous surface latent heart flux (SLHF) prior to the Gujarat earthquake of 26 January 2001. The surface latent heat flux shows an anomalous increase in SLHF prior to coastal earthquakes up to 14 days prior to the earthquake. In recent years, efforts have been made to study changes in surface latent heat flux prior to number of inland and coastal earthquakes of China. Abnormal changes in surface latent heat flux were found to be associated with several earthquakes around the world (Meihua et al., 2006; Li et al., 2009; Qin et al., 2009). Latent heat flux estimation depends on surface (ocean or land) temperature, air temperature, water vapor (WV) and relative humidity (Schulz et al., 1996; Gautam et al., 2005). The dependence of SLHF with various surface and air parameters

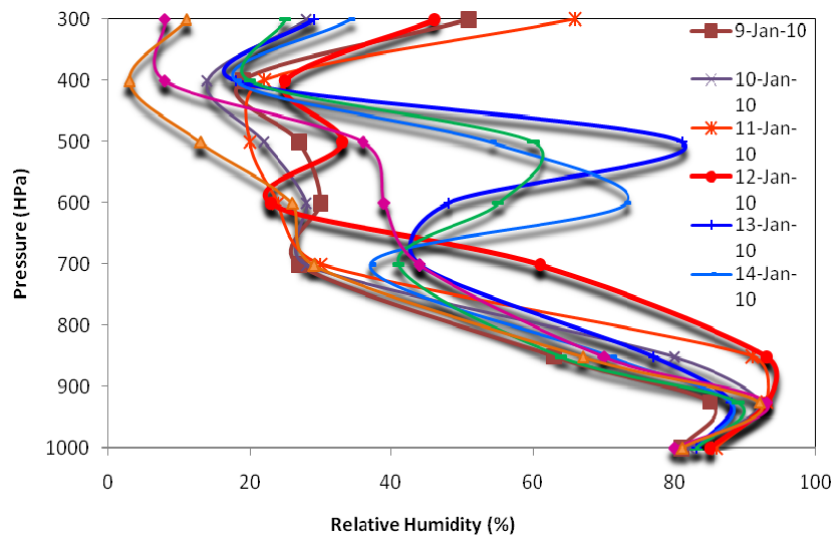

Fig. 3d. Vertical variation of relative humidity for the period 917 January 2010, the relative humidity shows a characteristic varition of relative humidity on the day of earthquake.

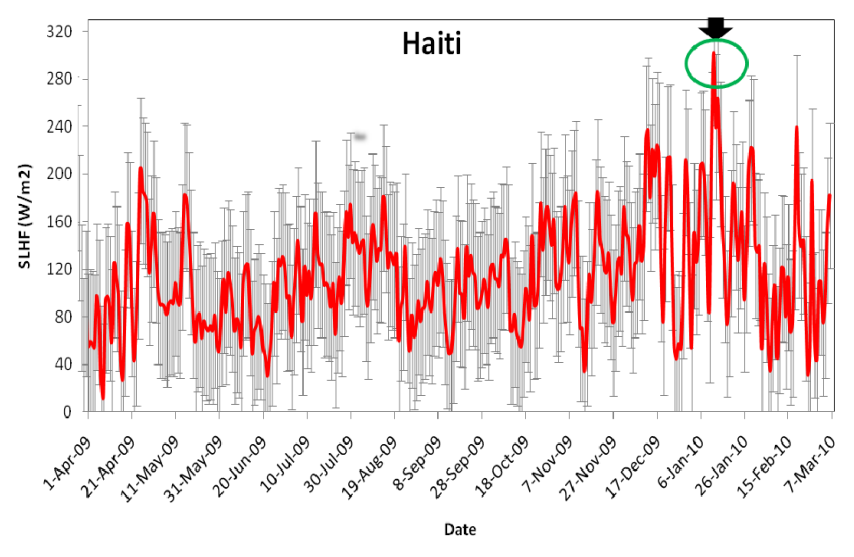

Fig. 4a. Figure 4a shows variation of daily surface latent heat flux. A maxima peak in surface latent heat flux is observed one day prior to the main earthquake event, error bars shows one standard deviation.

can be obtained from the following equation:

$\mathrm{LE}=\rho \mathrm{EC}_{\mathrm{D}}\left(U_{\mathrm{s}}-U_{\mathrm{a}}\right)\left(q_{\mathrm{s}}-q_{\mathrm{a}}\right)$

where the subscript a corresponds to a reference altitude, $\mathrm{s}$ stands for surface quantities, $C_{\mathrm{D}}$ is the bulk transfer coefficient, $q$ is the specific humidity, $U$ the scalar wind and $\rho$ and $E$ are constants.

Figure 4a shows daily variation of surface latent heat flux over the epicenter for the period from April 2009 to March 2010. A highest peak in SLHF is clearly seen one day prior to the main earthquake event on 12 January 2010. The error bars shows variations up to one standard deviation of daily surface latent heat flux. The value of surface latent heat flux is the highest daily value observed during April 2009 to March 2010. In Fig. 4b, the daily surface latent heat flux 


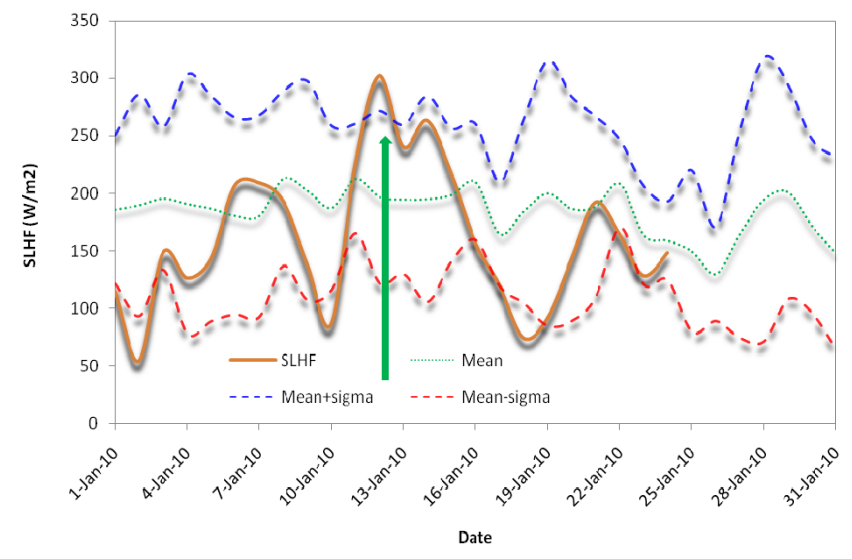

Fig. 4b. Figure 4b shows variation of daily surface latent heat flux. A maxima peak in surface latent heat flux is observed one day prior to the main earthquake event. This peak is found to be more than mean plus one sigma (standard deviation), Mean value is shown in dotted green color, mean + sigma is shown in dotted blue color and mean - sigma is shown with dotted red color.

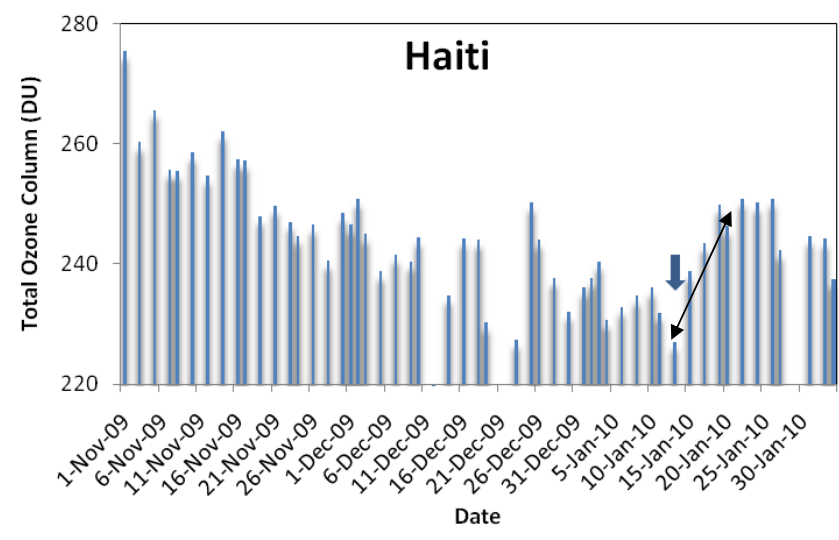

Fig. 5. Figure 5 shows variation of total ozone column (TOC), a drop in TOC is observed on the day of earthquake i.e. 12 January 2010, afterwards the TOC is found to be stable.

is shown for January 2010, a pronounced maxima peak in surface latent heat flux is clearly seen one day prior to the earthquake, the value of this peak is more than mean plus one sigma (standard deviation). The mean value is taken for the daily surface latent heat flux data for the period 20052010 which is shown in dotted green color, mean+sigma is shown in dotted blue color and mean - sigma is shown with dotted red color.

\subsection{Total ozone column}

The total ozone column (TOC) over the epicenter of earthquake is shown in Fig. 5. A sudden drop in TOC is observed soon after the earthquake, afterwards the TOC is found to be enhanced. Similar results are found in Gujarat earthquake of January 2001, Denali earthquake October 2003 and several earthquakes (Singh et al., 2006; Ganguly, 2009), i.e. pronounced drop in total ozone column on the day of earthquake and afterwards found to increase. In case of Haiti earthquake of 12 January 2010, we have found an increase of 20.316 DU (i.e. about $8.95 \%$ ) from one day after earthquake $(227.063 \mathrm{DU})$ and after a week the TOC value increased to 246.379 DU on 20 January 2010.

\section{Conclusions}

The present results clearly show changes in surface, atmosphere and total zone concentration, associated with the earthquake. The surface and air temperature, relative humidity and surface latent heat flux changes are showing complementary nature one day prior to the earthquake event. The atmospheric parameters at different pressure levels show a prominent characteristics one day prior the event compared to other days. In case of total ozone column, the characteristics of low value is observed on the day of earthquake, afterwards an increasing trend is clearly seen. Such characteristics of total ozone column is also found with other earthquakes (Singh et al., 2006; Ganguly, 2009). The complementary nature of surface and atmospheric parameters associated with Haiti earthquakes provide a strong evidence of lithosphere-atmosphere coupling.

Acknowledgements. The authors acknowledge the NCEP - NCAR for freely download of data and NASA Giovanni team for download of multi sensor data. The authors acknowledge the support of Sharda University to WM and MS. We are grateful to the reviewers for their comments and suggestions that have helped us to improve earlier versions of the manuscript.

Edited by: M. E. Contadakis

Reviewed by: A. Tronin and another anonymous referee

\section{References}

Bilham, R.: Lessons from the Haiti earthquake, Nature, 463, 878879, 2010.

Cioni, R., Guidi, M., Pierotti, L., and Scozzari, A.: An automatic monitoring network installed in Tuscany (Italy) for studying possible geochemical precursory phenomena, Nat. Hazards Earth Syst. Sci., 7, 405-416, doi:10.5194/nhess-7-405-2007, 2007.

Contadakis, M. E., Biagi, P. F., and Hayakwa, M. (Eds.): Ground and satellite based observations during the time of the Abruzzo earthquake, Special Issue, Nat. Hazards Earth Syst. Sci., http://www.nat-hazards-earth-syst-sci.net/special_ issue 102.html, 2009.

Dey, S. and Singh, R. P.: Surface latent heat flux as an earthquake precursor, Nat. Hazards Earth Syst. Sci., 3, 749-755, doi:10.5194/nhess-3-749-2003, 2003.

Dey, S., Sarkar, S., and Singh, R. P.: Anomalous changes in column water vapor after Gujarat earthquake, Adv. Space Res., 33, 274 278, 2004. 
Fierro, E. and Perry, C.: Preliminary Reconnaissance Report 12 January 2010 Haiti Earthquake, avaialable at: http://peer.berkeley.edu/publications/haiti_2010/documents/ Haiti_Reconnaissance.pdf, 2010.

Ganguly, N. D.: Variation in atmospheric ozone concentration following strong earthquakes, Int. J. Remote Sens., 30(1-2), 349356, 2009.

Gautam, R., Cervone, G., Singh, R. P., and Kafatos, M.: Characteristics of meteorological parameters associated with Hurricane Isabel, Geophys. Res. Lett., 32, L04801, doi:10.1029/2004GL021559, 2005.

Genzano, N., Aliano, C., Filizzola, C., Pergola, N., and Tramutoli, V.: A robust satellite technique for monitoring seismically active areas: The case of Bhuj-Gujarat earthquake, Tectonophysics, 431(1-4), 197-210, 2007.

Hayakawa, M. and Hobara, Y.: Current status of seismoelectromagnetics for short-term earthquake prediction, Geomatics, Natural Hazards and Risk, 1(2), 115-155, 2010.

Li, J., Wu, L., Wu, H., Liu, S., and You, J.: Surface latent heat flux prior to major coastal earthquakes in China, PIERS, Beijing, China, March 23-27, 827-830, 2009.

Meihua, C., Zhihui, D., Zhuzhuan, Y., and Xiaojing, M.: Surface latent heat flux anomalies prior to the Indonesia Mw9.0 earthquake of 2004, Chinese Sci. Bull., 51, 1010-1013, 2006.

Okada, Y., Mukai, S., and Singh, R. P.: Changes in atmospheric aerosol parameters after Gujarat earthquake of January 26, 2001, Adv. Space Res., 33, 268-273, 2004.

Qin, K., Guo, G., and Wu, L.: Surface latent heat flux anomalies preceding inland earthquakes in China, Earthquake Science, 22, 1674-4519, 2009.

Sharma, K., Das, R. M., Dabas, R. S., Pillai, K. G. M., Garg, S. C., and Mishra, A. K.: Ionospheric precursors observed at low latitudes around the time of Koyna earthquake, Adv. Space Res., 42(7), 1238-1245, doi:10.1016/j.asr.2007.06.26, 2007.

Schulz, J., Jeans, M., Stefan, E., and Schlussel, P.: Evaluation of satellite derived latent heat flux, J. Climate, 10, 2782-2795, 1996.

Singh, R. P., Bhoi, S., and Sahoo, A. K.: Significant changes in the ocean parameters after the Gujarat earthquake, Current Science, 80(11), 1376-1377, 2001a.
Singh, R. P., Bhoi, S., Sahoo, A. K., Raj, U., and Ravindran, S.: Surface manifestations after the Gujarat earthquake, Current Science, 81(2), 164-166, 2001b.

Singh, R. P., Sahoo, A. K., Bhoi, S., Kumar, M. G., and Bhuiyan, C. S.: Ground Deformation of the Gujarat Earthquake of 26 January 2001, J. Geol. Soc. India, 58, 209-214, 2001c.

Singh, R. P., Bhoi, S., and Sahoo, A. K.: Changes observed on land and ocean after Gujarat earthquake 26 January 2001 using IRS data, Int. J. Remote Sens., 23, 3123-3128, 2002.

Singh, R. P., Dey, S., Bhoi, S., Sun, D., Cervone, G., and Kafatos, M.: Anomalous increase of chlorophyll concentrations associated with earthquakes, Adv. Space Res., 37, 671-680, 2006.

Singh, R. P., Cervone, G., Singh, V. P., and Kafatos, M.: Generic precursors to coastal earthquakes: Inferences from Denali fault earthquake, Tectonophysics, 431(1-4), 231-240, 2007.

Singh, R. P., Kumar, S. J., Zlotnicki, J., and Kafatos, M. K.: Satellite detection of Carbon monoxide emission prior to the Gujarat earthquake of 26 January 2001, Appl. Geochem., 25, 580-585, 2010a.

Singh, R. P., Mehdi, W., Gautam, R., J. Senthilkumar, Zlotnicki, J., and Kafatos, M.:, Precursory Signals Using Satellite and Ground data Associated with the Wenchuan Earthquake of 12 May, 2008 , Int. J. Remote Sens., 311(12), 1-14, 2010 b.

Tronin, A., Hayakawa, M., and Molchanov, O. A.: Thermal IR satellite data application for earthquake research in Japan and China, J. Geodyn., 33, 519-534, 2002.

Trigunait, A., Parrot, M., Pulinets, S., and Li, F.: Variation of the ionospheric electron density during the Bhuj seismic event, Ann. Geophys., 22, 4123-4131, 2004, http://www.ann-geophys.net/22/4123/2004/.

Walia, V., Virk, H. S., and Bajwa, B. S.: Radon precursory signals for some earthquakes of magnitude $>5$ occurred in $\mathrm{N}-\mathrm{W}$ Himalaya: An overview, Pure Appl. Geophys., 163, 711-721, 2006.

Yasuka, Y., Igarashi, G., Ishikawa, T., Tokonami, S., and Shinogi, M.: Evidence of precursor phenomena in the Kobe earthquake obtained from atmospheric radon concentration, Appl. Geochem., 21, 1064-1072, 2006. 